\title{
Leadership styles and quality of work life in SMEs
}

\author{
T. S. Nanjundeswaraswamy ${ }^{a^{*}}$ and D.R. Swamy D R ${ }^{b}$
}

\begin{tabular}{l}
${ }^{a}$ Assistant Professor, Department of In \\
${ }^{b}$ Professor, Department of Industrial E \\
\hline C H R O N I C L E \\
\hline Article history: \\
Received September 18, 2014 \\
Accepted 9 December 2014 \\
Available online \\
December 102014 \\
\hline Quality of Work Life \\
SMEs \\
Leadership styles \\
Transformational \\
Leadership \\
Transactional leadership
\end{tabular}

\section{Introduction}

India values Small and Medium Enterprises (SMEs) for several reasons, such as their potential to create employment and to generate foreign currencies through export, and also their potential to grow into Larger Enterprises (LEs). These enterprises are important as domestic producers of cheap import substitution consumer goods especially for low income groups, and as supporting industries producing components, tools, and spare parts for LEs. Since SMEs plays an important role in the country's economy, employee's satisfaction working in these SMEs should be given lot of emphasis. It is not possible to design jobs solely grounded on the needs of technology completely overlooking the needs of employees. There is an all-round demand for developing the humanized jobs, which can satisfy workers with respect to their job and work environment. The jobs need to be excellent both from the

\footnotetext{
*Corresponding author.

E-mail addresses: nswamy.ts@gmail.com (T. S. Nanjundeswaraswamy)

(C) 2015 Growing Science Ltd. All rights reserved.

doi: $10.5267 /$ j.ms 1.2014 .12 .006
} 
point of view of technology and human needs. In view of this, the traditional job design needs to be replaced by enriched job design. This demand for redesigning of jobs is come to known as Quality of Work Life (QWL). It enjoins management to treat workers as resources that are to be developed rather than simply used. The scope of QWL movement which originally included only job redesign process based on the socio-technical systems approach but gradually this concept broadened by considering wide variety of interventions such as quality circles, suggestion schemes, employee participation, empowerment, autonomous work teams, etc. These interventions ensure the full use of a worker's potential by assuring greater involvement of workers, which makes the work more effective and efficient by enhancing the quality.

An effective leader influences followers in specific manner to achieve desired goal; different leadership styles may affect organizational performance Nahavandi (2006). Transformational leadership is a stronger predictor of both job satisfaction and overall employee satisfaction Yair et al. (2003). Ogbonna and Harris (2002) noted that organizational performance is influenced by a competitive and innovative culture. Organizational Culture is influenced by leadership style and subsequently, leadership style affects organizational performance.

The purpose of this research is to gain insight on QWL and Leadership styles among the employees in Mechanical Manufacturing SMEs. Further, research also attempts to identify the relationship among leadership styles and QWL. Therefore, it is essential to explore the status of employees QWL in SMEs in order to explore the present leadership styles and to analyze the relationship of different leadership styles with different dimensions of QWL.

\section{Literature review}

\subsection{Quality of Work Life}

Hackman and Oldham (1980) described QWL as the favorable working environment that supports and promoted satisfaction by providing employees with rewards, job security and career growth opportunities. The work environment enables to fulfill employees' personal needs is considered as an important factor to provide a positive interaction effect, which will lead to an excellent QWL. Cunningham and Eberle (1990) emphasized that the personal needs are satisfied when rewards from the organization, such as compensation, promotion, recognition and development meet their expectations. The elements that are relevant to an individual's QWL include the task, the physical and social work environment within the organization, organizational system and relationship between life on and off the job.

Chan and Einstein (1990) explained QWL reflects as a concern for people's experience at work, their relationship with other people, their work setting and their effectiveness on the job. European Foundation for the Improvement of Living Conditions 2002 described that the QWL is a multidimensional construct, made up of a number of interrelated factors that need careful consideration to conceptualize and measure. QWL is associated with job satisfaction, job involvement, motivation, productivity, health, safety, job security, competence development and balance between work and nonwork life. Quality of work life is a process by which an organization responds to employee needs for developing mechanisms to allow them to share fully in making the decisions that design their lives at work. Saraji and Dargahi (2006) study explained QWL as a comprehensive, department wide program designated to improve employee satisfaction, strengthening workplace learning and helping employees had better manage, change and transition by conducting descriptive and analytical study.

QWL programs will benefit both employees and management, by mutually solving work related problems, building cooperation, improving work environments, restructuring tasks carefully and fairly managing human resource outcomes and payoffs according to the study of Rose et al. (2006). 
According to Rethinam and Ismail (2007), QWL is a multi-dimensional construct, made up of a number of interrelated factors that need careful consideration to conceptualize and measure. It is associated with job satisfaction, job involvement, motivation, productivity, health, safety and well-being, job security, competence development and balance between work and non-work life and also he concluded as QWL from the perspective of IT professionals is challenging both to the individuals and organizations.

However, from the literature it can be summarized that QWL may be viewed as a wide-ranging concept, which includes satisfaction towards work, participative management and improve work environment. It is evident from the available literature, there is very less research work has been undertaken in SMEs area. Based on the available literature important Nine Quality of Work Life components are considered for the present research, they are: Work environment, Organization culture and climate, Relation and cooperation, Training and development, Compensation and Rewards, Facilities, Job satisfaction and Job security, Autonomy of work, Adequacy of resources, which are more appropriate for Indian manufacturing SMEs.

\subsection{Leadership Styles}

Leadership is a social influence process in which the leader seeks the voluntary participation of subordinates in an effort to reach organization goals (Omolayo, 2007). Today's organizations need effective leaders who understand the complexities of the rapidly changing global environment. If the task is highly structured and the leader has good relationship with the employees, effectiveness will be high on the part of the employees (Smith, 1998). Smith's study further revealed that democratic leaders take great care to involve all members of the team in discussion, and can work with a small but highly motivated team. Barchiesi and La Bella (2007) measures the leadership effectiveness, leadership role and its influence on performance, leadership behaviors and attitudes. It was found that high leadership indexes are not related to past performance records, but it is associated with higher potentiality of enhanced performance and higher reputation of organization pointing in the direction of a meaningful influence of behavioral complexity and dynamics on the leadership perceived level. Voonl et al. (2011) used the factors like salaries, job autonomy, job security, workplace flexibility to investigate the relationship between leadership styles and employee job satisfaction, study revealed that transformational leadership style has a stronger relationship with job satisfaction.

Fang et al. (2009) identified that leadership style can affect organizational commitment, job satisfaction positively and job satisfaction intern can affect organizational commitment and performance. Leadership is largely culturally orientated, embracing traditional beliefs, norms and values, and a preoccupation (Prideaux \& Be, 2007). According to Victor and Soutar (2005), leadership style is significantly influenced by the leader's immediate and extended family, clan, and tribe. This study finds the linkages between organizational leadership and business ethics, thereby making a contribution toward increasing the quality of organizational life which may have a positive influence on both members of the organization and the wider community. Ye et al. (2011) explained that employees' perceptions about transactional or transformational leadership style of executive, both have highly positive correlation with perceptions about executive's encouragement factors of its innovation climate.

According to Podsakoff et al. (1990), leadership behavior can affect trust and satisfaction of employees to organization and organizational citizenship behavior, further enhances the relationship between leadership style and organizational commitment directly. Mc Neese-Smith D (1995) explained how leadership behavior of hospital directors significantly positively and related to productivity, work satisfaction and organizational commitment of staff. Transactional leadership is considered as the subordinates' rewards though their efforts and performance. Wang (2008) compared the Transactional leadership, Transformational leadership theory is deemed to improve the subordinates' performance by changing the motives and values of employees. Bernard et al. (1990) divided leadership style into 
transformational leadership and transactional leadership. Transformational leadership has the characteristics of individual influence, spiritual encouragement and intellectual stimulation. They often take individual into consideration, establish vision and aim inside, create open culture, trust the staff to reach their goals and give full play for staff's potential. Transactional leadership is focused on staff's basic and external demand, the relationship between leaders and subordinates is based on the contract. They tend to attain organizational goal by pacific job roles and mission design, their basic purpose is to maintain a stable organization. However from the available literature it can summarize the different types of leadership styles and their effect on employee satisfaction, team work, organizational change and employee performance. From the literature review it is identified that these styles need to be evaluated with respect to the components of Quality of Work Life, which are more appropriate for Indian Mechanical Manufacturing SMEs.

\section{QWL model}

The framework of QWL is developed on the basis of the theoretical model of QWL implementation components. Thus, the framework of QWL consists of nine components (See Fig. 1).

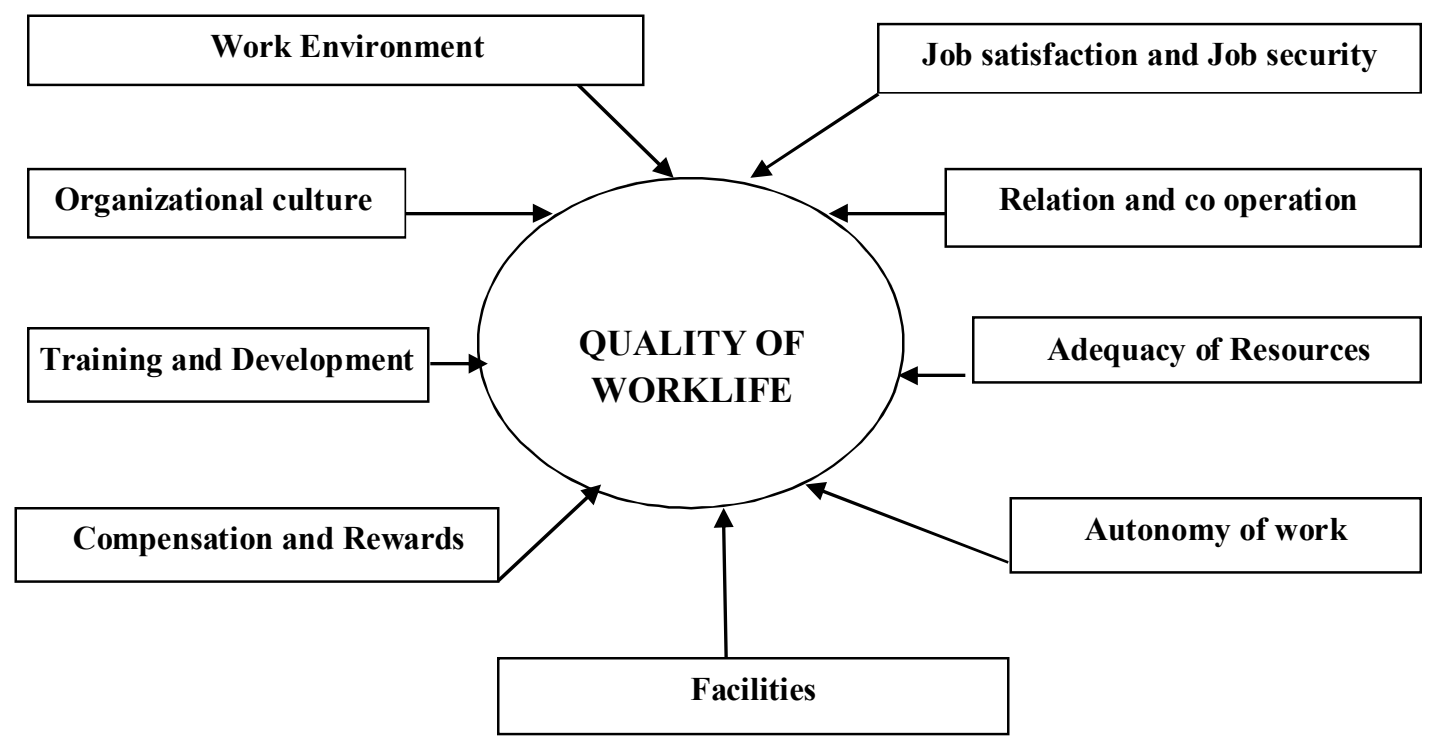

Fig. 1. QWL Model

\section{Hypothesis}

Cooper and Schindler (1998) explained the purpose of hypothesis testing is to determine the accuracy of the study, hypotheses due to the fact that the researchers have collected a sample of data, not a census. In hypothesis testing the main question is: whether to accept the null hypothesis or not to accept the null hypothesis Kothari (2004). Independent variable in the present study QWL of employees. The dependent variables are components of QWL. Nine components pertaining to Quality of Work Life of employees that were identified formed the basis for the constructs of the independent variables.

In the light of above objectives the following main hypothesis were identified.

1. Association of QWL with demographical characteristics of firms

2. Association of leadership styles with demographical characteristics of firms

3. Association of QWL with leadership styles

4. Association of components of QWL and leadership styles 


\section{Conceptual model}

The frame works of the proposed study consist of nine components of QWL and two types of leadership style transformational leadership style and transactional leadership style. Fig. 2 shows the conceptual framework for the present research on quality of work life and leadership styles. Nine dimensions of Quality of Work Life are Work environment, Organization culture and climate, Relation and cooperation, Training and development, Compensation and Rewards, Facilities, Job satisfaction and Job security, Autonomy of work, Adequacy of resources. Two types of leadership styles i.e. transformational leadership style and transactional leadership styles.

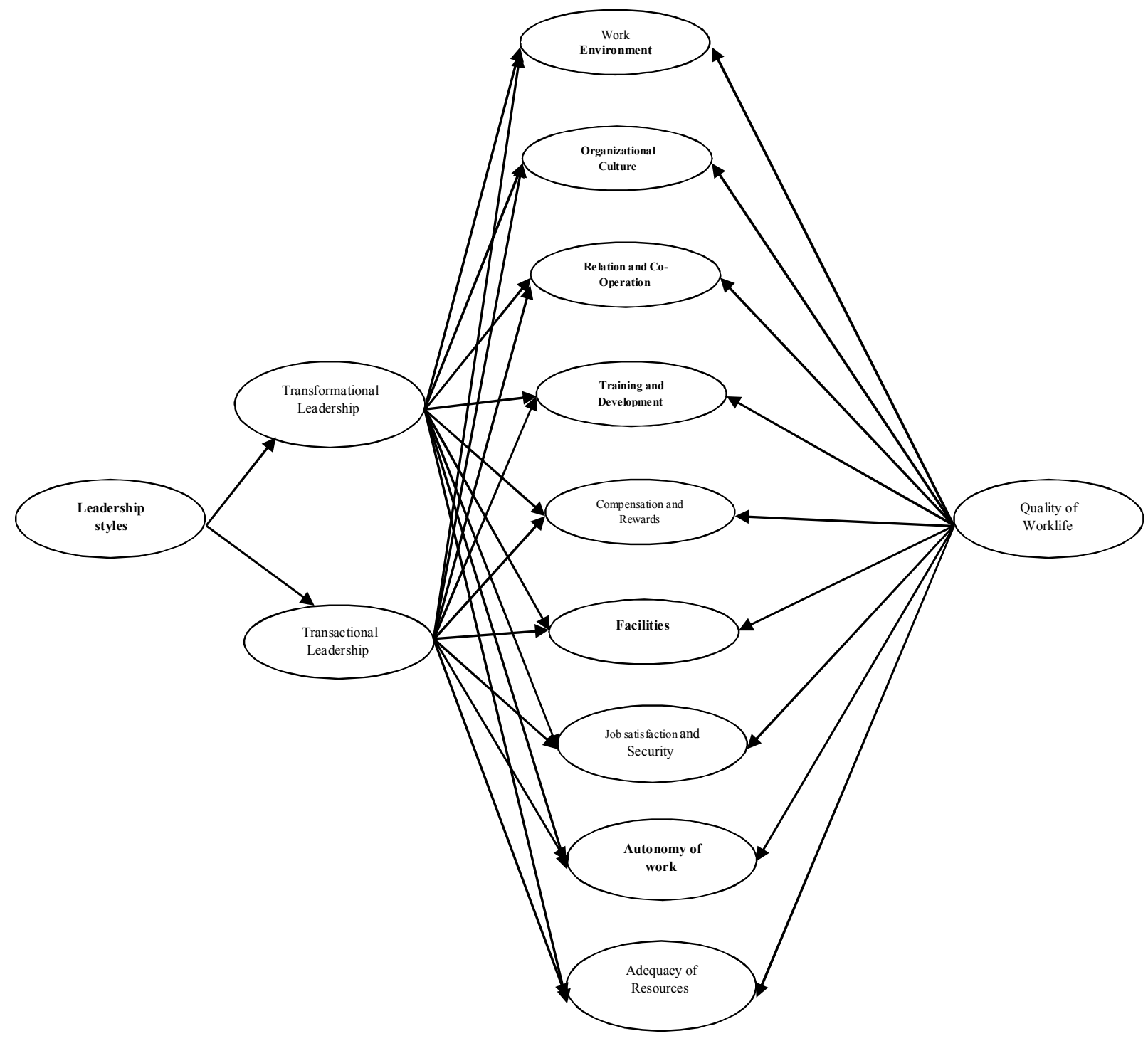

\section{Sample size}

Fig. 2. Conceptual Framework

To represent the population reasonably, a sample of size " $n$ " is selected using the following formula found in Hogg and Tannis (1997), and Bartlett et al. (2001)

$$
n=\frac{m}{\left[1+\frac{m-1}{N}\right]}
$$


where

$$
\begin{gathered}
\mathrm{n}=\text { Sample size } \\
\mathrm{N}=\text { Population size } \\
m=\frac{\left[Z^{2} \times P \times(1-P)\right]}{\varepsilon^{2}}
\end{gathered}
$$

where

$Z=1.96$ for $95 \%$ confidence level

$\mathrm{P}=$ Preliminary estimate of percentage $(80 \%$ i e 0.8$)$

$\varepsilon=$ Accuracy desired (5\% i.e. 0.05$)$

$$
\text { Sample size }=\frac{\left[1.96^{2} \times 0.8 \times(1-0.8)\right]}{0.05^{2}}=245.86 \approx 246
$$

For this $m$ value and the population size $=3789$, the sample size " $n$ " is determined as

$$
n=\frac{246}{1+\frac{246-1}{3789}}=231.05 \approx 231
$$

Thus, the minimum sample size for the study is 231 . The data was collected through a specially designed questionnaire administered to the 1500 employees of 300 mechanical manufacturing SMEs surveyed. 1147 employees responded of 248 firms was collected. Out of that 1092 questionnaire from 240 firms were found to be valid, appropriate and considered for the final analysis. The responses of remaining are 55 questionnaires of 8 firms are rejected because of illegible, inappropriate and incomplete data.

\section{Questionnaire development}

Since the research is not a replication of any previous studies, the questionnaire was developed through literature review and a mix and match approach was undertaken to modify the sentence wherever necessary to suit the local context.

The questionnaire was designed both in Kannada and English language. In order to standardize the instrument (Questionnaires) its reliability coefficient was calculated and it was found to be 0.88 Cronbach's alpha value.

The structured final questionnaire designed for the study was 'closed ended' by nature. The questionnaire consisted of mainly three important sections namely,

1. Firm's general Demographic information

2. Employees Perception towards Quality of Work Life

3. Employees opinion about leadership styles

Each section had multiple questions to cover different parameters with a Five-point Likert scale with " 1 " being "strongly disagree" and " 5 " being "strongly agree" was used. The questionnaire consist 60 close-ended questions. Out of those 60 questions, 50 questions were related to quality of Work Life and 10 questions were related to leadership styles. Under Quality of Work Life nine components are considered for the study they are work environment, organization culture and climate, Relation and cooperation, Training and development, Compensation and Rewards, Facilities, Job satisfaction and Job security, Autonomy of work, Adequacy of resources. Under Leadership styles two types of leadership styles was considered for the study they are, Transformational leadership style and Transactional leadership style. Transformational leadership style was measured by four subscales which are 
Charisma, Individualized Consideration, Inspirational Motivation, and Intellectual Stimulation. Transactional leadership style was measured by two subscales which are Contingent rewards and management-by-exception. Responses were recorded on 5-point Likert scale, "1" being "strongly disagree" and " 5 " being "strongly agree" was used. A database is developed to incorporate and process the surveyed data. This database was designed with MS Excel and Mini Tab 14 software. The responses of the final questionnaire are fed into the designed data base for the purpose of analysis and report generation.

\section{Findings}

\subsection{Quality of Work Life in SMEs}

To find the status of QWL in SMEs, the average QWL score of employees for each firm was determined. This grand mean score was then used to categorize the firms QWL. Firms were divided into two groups, satisfied and unsatisfied based on the QWL score. The two categories of quality of Work Life level were determined by dividing the range of possible QWL scores (1-5) into two intervals. Those scoring more than overall mean on the QWL were assigned the satisfied and less than overall mean were assigned as unsatisfied. The weights for the respondent's choices are summed across all statements in each industry. On the basis's of the mean score industries are classified into two groups i.e. QWL satisfied and QWL not satisfied.

\section{Table 1}

Quality of Work Life in SMEs

\begin{tabular}{lll}
\hline Perception & No of Industries & Percentage \\
\hline Satisfied & 58 & 24.20 \\
Unsatisfied & 182 & 75.80 \\
\hline Total & 240 & 100 \\
\hline
\end{tabular}

Table 1 shows out of 240 SMEs only in 48 (24.2 percent) industries QWL is satisfied and in remaining 182 (75.80 percent) industries QWL is not satisfied according to the survey.

\subsection{Leadership styles in SMEs}

Surveyed SMEs are grouped into two on the basis of type of leadership styles adopted in the workplace, based on the opinion of 1092 employees from 240 SMEs. Based on their opinion about their superior leadership styles SMEs are categorized into Transformational leadership style adopted SMEs and Transactional leadership styles adopted SMEs. On the basis of mean score the type of the leadership style was decided.

Table 2

Leadership styles according to industries wise

\begin{tabular}{lcc}
\hline Leadership styles & No of Industries & Percentage \\
\hline Transformational & 136 & 56.66 \\
Transactional & 104 & 43.34 \\
\hline Total & 240 & 100 \\
\hline
\end{tabular}

The above Table 2 shows that out of 240 surveyed SMEs, 136 (56.66 Percent) SMEs are following Transformational Leadership styles and remaining 104 (43.34 Percent) SMEs are following Transactional leadership styles according to employee opinion.

\subsection{Leadership styles and Quality of work life in SMEs}

Surveyed 240 SMEs are grouped into two based on the type of leadership styles what they are adopted in the firm, out of that in 136 SMEs adopted Transformational Leadership styles and in 104 SMEs are adopted Transactional Leadership styles. 


\subsection{Quality of work life under Transformational leadership styles}

Surveyed 136 Transformational leadership style SMEs are grouped into two based on the QWL of employees. The table below shows the QWL of employees under transformational leadership styles.

\section{Table 3}

Quality of Work Life under Transformational leadership styles

\begin{tabular}{ll}
\hline Perception & No of Industries \\
\cline { 1 - 2 } Satisfied & 39 \\
Unsatisfied & 97 \\
\hline Total & 136 \\
\hline
\end{tabular}

Among 136 SMEs, only in 39 SMEs having good QWL and in reaming 97 SMEs have poor QWL Under transformational Leadership styles.

\subsection{Quality of work life under Transactional leadership styles}

Surveyed 104 Transactional leadership style SMEs are grouped into two based on the QWL of employees. The table below shows the QWL of employees under transactional leadership styles.

\section{Table 4}

Quality of Work Life under Transactional leadership styles

\begin{tabular}{ll}
\hline Perception & No of Industries \\
\hline Satisfied & 19 \\
Unsatisfied & 85 \\
\hline Total & 104 \\
\hline
\end{tabular}

Among 104 SMEs, only in 19 SMEs having good QWL and in reaming 85 SMEs have poor QWL Under transactional Leadership styles.

\subsection{Status of QWL Components under transformational leadership style in SMEs}

Under transformational leadership style surveyed 136 industries are classified into two groups one is satisfied other one is unsatisfied on the basis of mean score below table shows the status of QWL components.

\section{Table 5}

Status of QWL Components under Transformational leadership style in SMEs

\begin{tabular}{llcc}
\hline \multirow{2}{*}{ S1 No } & \multirow{2}{*}{ Components of QWL } & \multicolumn{2}{c}{ No of SMEs } \\
\cline { 3 - 4 } & Work Environment & Satisfied & Unsatisfied \\
\hline 2 & Organization Culture & 42 & 94 \\
3 & Relation \& Co operation & 41 & 95 \\
4 & Training \& Development & 43 & 99 \\
5 & Compensation \& Rewards & 37 & 99 \\
6 & Facilities & 37 & 103 \\
7 & Job satisfaction \& Job security & 33 & 98 \\
8 & Autonomy of work & 38 & 96 \\
9 & Adequacy of Resources & 40 & 103 \\
\hline
\end{tabular}


The above Table 5 shows that under transformational leadership style approximately about 30 percent of SMEs are have good status of QWL components and remaining 70 percent of SMEs have poor QWL components in their firms.

\subsection{Status of QWL Components under Transactional leadership style in SMEs}

Under Transactional leadership style surveyed 104 industries are classified into two groups one is satisfied other one is unsatisfied on the basis of mean score below table shows the status of QWL components.

\section{Table 6}

Status of QWL Components under Transactional leadership style in SMEs

\begin{tabular}{llcc}
\hline \multirow{2}{*}{ S1 No } & Components of QWL & Satisfied & No of SMEs \\
& & 18 & 86 \\
\hline 1 & Work Environment & 20 & 84 \\
2 & Organization Culture & 19 & 85 \\
3 & Relation \& Co operation & 21 & 83 \\
4 & Training \& Development & 21 & 83 \\
5 & Compensation \& Rewards & 26 & 78 \\
6 & Facilities & 24 & 80 \\
7 & Job satisfaction \& Job security & 16 & 88 \\
8 & Autonomy of work & 26 & 78 \\
9 & Adequacy of Resources & & \\
\hline
\end{tabular}

The above Table 6 shows that under Transactional leadership style approximately about 20 percent of SMEs are have good status of QWL components and remaining 80 percent of SMEs have poor QWL components in their firms.

\section{Analyses and discussion}

The data are classified into convenient tables to enable comparison and tests of association of attributes. The results are presented to bring out status of QWL, Transformational leadership styles and Transactional leadership in these SMEs.

\subsection{Demographical Factors of Industries and Quality of Work Life in SMEs}

The SMEs are classified into satisfied and unsatisfied firms for all demographical characteristics and are presented in Table 7. Also presented the values of $\chi^{2}$ and their significance levels (if significant) for testing the association between Quality of Work Life and each of the demographic characteristics of the firms studied.

\section{Table 7}

Demographical Factors of Industries and Quality of Work Life in SMEs

\begin{tabular}{|c|c|c|c|c|c|c|c|c|}
\hline $\mathrm{Sl}$ & & nographical Factor & Satisfied & Unsatisfied & $\chi^{2}$ & $\chi^{2}$ & $\mathrm{P}$ value & Significance \\
\hline \multirow{4}{*}{1} & $4=$ & Less than 10 years & 27 & 79 & \multirow{4}{*}{7.81} & \multirow{4}{*}{0.235} & \multirow{4}{*}{0.972} & \multirow{4}{*}{ NS } \\
\hline & 品 & 11 to 20 years & 21 & 71 & & & & \\
\hline & 800 & 21 to 30 years & 4 & 14 & & & & \\
\hline & $\varangle \nsubseteq$ & Above 31 years & 6 & 18 & & & & \\
\hline \multirow{4}{*}{2} & $4=$ & Less than 10 & 11 & 50 & \multirow{4}{*}{7.81} & \multirow{4}{*}{3.67} & \multirow{4}{*}{0.299} & \multirow{4}{*}{ NS } \\
\hline & 泟 & 11 to 25 & 16 & 57 & & & & \\
\hline & 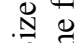 & 26 to 50 & 19 & 52 & & & & \\
\hline & $\bar{\omega} \cong$ & More than 51 & 12 & 23 & & & & \\
\hline \multirow{4}{*}{3} & 4 & Less than 10 & 12 & 33 & \multirow{4}{*}{7.81} & \multirow{4}{*}{0.744} & \multirow{4}{*}{0.863} & \multirow{4}{*}{ NS } \\
\hline & 0 & 11 To 25 & 9 & 36 & & & & \\
\hline & $\overrightarrow{0} 0$ & 26 To 50 & 18 & 59 & & & & \\
\hline & $U$ & More than 51 lakhs & 19 & 54 & & & & \\
\hline
\end{tabular}


Quality of Work Life in the SMEs is independent of the age of the firm, size of the firm and cost of the project. Among these three demographical factor size of the firm, the difference between $\chi^{2}$ calculated and $\chi^{2}$ table value is less that indicates that size of the firm has very less influence on the QWL in the firms.

\subsection{Demographical Factors of Industries and leadership styles in SMEs}

The SMEs are classified into transformational leadership style and transactional leadership style SMEs for all demographical characteristics of the firms and are presented in Table 8. Also presented the values of $\chi^{2}$ and their significance levels (if significant) for testing the association between different leadership styles and each of the demographic characteristics of the firms studied.

Table 8

Demographical Factors of Industries and leadership styles in SMEs

\begin{tabular}{|c|c|c|c|c|c|c|c|c|}
\hline $\begin{array}{c}\text { Sl } \\
\text { No }\end{array}$ & \multicolumn{2}{|c|}{ Demographical Factor } & $\begin{array}{c}\text { Transformational } \\
\text { Leadership }\end{array}$ & $\begin{array}{c}\text { Transactional } \\
\text { leadership }\end{array}$ & $\begin{array}{c}\chi^{2} \\
\text { table } \\
\text { Value }\end{array}$ & $\begin{array}{c}\chi^{2} \\
\text { calculated } \\
\text { Value }\end{array}$ & $\begin{array}{c}\mathrm{P} \\
\text { value }\end{array}$ & $\begin{array}{c}\text { Significance } \\
\text { Level }\end{array}$ \\
\hline \multirow{4}{*}{1} & & Less than 10 years & 62 & 44 & \multirow{4}{*}{7.81} & \multirow{4}{*}{2.432} & \multirow{4}{*}{0.488} & \multirow{4}{*}{ NS } \\
\hline & ○ & 11 to 20 years & 47 & 45 & & & & \\
\hline & 80 & 21 to 30 years & 11 & 7 & & & & \\
\hline & $\varangle \doteq$ & Above 31 years & 16 & 8 & & & & \\
\hline \multirow{4}{*}{2} & & Less than 10 & 34 & 27 & \multirow{4}{*}{7.81} & \multirow{4}{*}{0.671} & \multirow{4}{*}{0.880} & \multirow{4}{*}{ NS } \\
\hline & ○ & 11 to 25 & 39 & 34 & & & & \\
\hline & 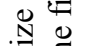 & 26 to 50 & 42 & 29 & & & & \\
\hline & $\dot{n} \equiv$ & More than 51 & 21 & 14 & & & & \\
\hline \multirow{4}{*}{3} & & Less than 10 & 21 & 24 & \multirow{4}{*}{7.81} & \multirow{4}{*}{3.784} & \multirow{4}{*}{0.286} & \multirow{4}{*}{ NS } \\
\hline & & 11 To 25 & 24 & 21 & & & & \\
\hline & $\ddot{0}$ & 26 To 50 & 47 & 30 & & & & \\
\hline & $\begin{array}{l}\overrightarrow{0} \\
0 \\
0\end{array}$ & $\begin{array}{l}\text { More than } 51 \\
\text { lakhs }\end{array}$ & 46 & 27 & & & & \\
\hline
\end{tabular}

Age of the firm, Size of the firm and Cost of the firm is not significantly associated with Transformational leadership style and transactional leadership style. That is type of the leadership styles is independent of age of the firms, Size of the firm and Cost of the firm.

\subsection{Leadership styles and Quality of Work Life Industry wise}

Table 9

Leadership styles and Quality of Work Life Industry wise

\begin{tabular}{llllcccc}
\hline $\begin{array}{c}\text { Sl } \\
\text { No }\end{array}$ & Quality of Work Life & Satisfied & Unsatisfied & $\begin{array}{c}\chi^{2} \\
\text { table } \\
\text { Value }\end{array}$ & $\begin{array}{c}\chi^{2} \\
\text { calculated } \\
\text { Value }\end{array}$ & $\begin{array}{c}\text { P } \\
\text { value }\end{array}$ & $\begin{array}{c}\text { Significance } \\
\text { Level }\end{array}$ \\
\hline \multirow{2}{*}{$\begin{array}{llllll}\text { Leadership } \\
\text { styles }\end{array}$} & Transformational & 46 & 90 & 3.84 & 7.22 & 0.007 & $5 \%$ \\
\hline
\end{tabular}

Quality of Work Life of SMEs has significant association with the types of the leadership styles. That is Quality of Work Life in SMEs is independent on transformational leadership style and transactional leadership style

\subsection{Leadership styles and Components of Quality of work life industry wise}

1. QWL components like Work environment, relation and co-operation, autonomy of work has a significant association with leadership style. 
2. QWL components like training and development, compensation and reward, facilities, job satisfaction and job security and adequacy of resources are not associated with leadership style.

3. In case of Organizational culture and climate the $p$ value is approximately equal to 0.05 , this indicates that leadership styles have some impact on organizational culture and climate.

\section{Table 10}

Leadership styles and Components of Quality of Work Life industry wise

\begin{tabular}{|c|c|c|c|c|c|c|c|c|}
\hline $\begin{array}{l}\text { Sl } \\
\text { No }\end{array}$ & QWL Components & Leadership styles & Satisfied & Unsatisfied & $\begin{array}{c}\chi^{2} \\
\text { table } \\
\text { Value }\end{array}$ & $\begin{array}{c}\chi^{2} \\
\text { calculated } \\
\text { Value }\end{array}$ & $\begin{array}{c}\mathrm{P} \\
\text { value }\end{array}$ & $\begin{array}{c}\text { Significance } \\
\text { Level }\end{array}$ \\
\hline \multirow{2}{*}{1} & \multirow{2}{*}{ Work Environment } & Transformational & 42 & 94 & \multirow{2}{*}{3.84} & \multirow{2}{*}{5.792} & \multirow{2}{*}{0.016} & \multirow{2}{*}{$5 \%$} \\
\hline & & Transactional & 18 & 86 & & & & \\
\hline \multirow{2}{*}{2} & Organization & Transformational & 41 & 95 & \multirow{2}{*}{3.84} & \multirow[t]{2}{*}{3.705} & \multirow[t]{2}{*}{0.054} & \multirow{2}{*}{ NS } \\
\hline & Culture and climate & Transactional & 20 & 84 & & & & \\
\hline \multirow{2}{*}{3} & Relation and co & Transformational & 43 & 93 & \multirow{2}{*}{3.84} & \multirow[t]{2}{*}{5.481} & \multirow[t]{2}{*}{0.019} & \multirow{2}{*}{$5 \%$} \\
\hline & operation & Transactional & 19 & 85 & & & & \\
\hline \multirow{2}{*}{4} & Training and & Transformational & 37 & 99 & \multirow{2}{*}{3.84} & \multirow[t]{2}{*}{1.582} & \multirow[t]{2}{*}{0.208} & \multirow{2}{*}{ NS } \\
\hline & development & Transactional & 21 & 83 & & & & \\
\hline \multirow{2}{*}{5} & Compensation and & Transformational & 37 & 99 & \multirow[b]{2}{*}{3.84} & \multirow[t]{2}{*}{1.582} & \multirow[t]{2}{*}{0.208} & \multirow{2}{*}{ NS } \\
\hline & Rewards & Transactional & 21 & 83 & & & & \\
\hline \multirow{2}{*}{6} & \multirow{2}{*}{ Facilities } & Transformational & 33 & 103 & \multirow{2}{*}{3.84} & \multirow[t]{2}{*}{0.017} & \multirow[t]{2}{*}{0.896} & \multirow{2}{*}{ NS } \\
\hline & & Transactional & 26 & 78 & & & & \\
\hline \multirow{2}{*}{7} & \multirow{2}{*}{$\begin{array}{l}\text { Job satisfaction and } \\
\text { job security }\end{array}$} & Transformational & 38 & 98 & \multirow{2}{*}{3.84} & 0.728 & 0.394 & NS \\
\hline & & Transactional & 24 & 80 & & & & 1V \\
\hline 8 & Autonomy of work & Transformational & 40 & 96 & 384 & 6.482 & 0.011 & $5 \%$ \\
\hline 8 & Autonomy or work & Transactional & 16 & 88 & 3.04 & & & $5 \%$ \\
\hline 9 & Adequacy of & Transformational & 33 & 103 & 384 & 0.017 & 0.896 & NS \\
\hline 9 & Resources & Transactional & 26 & 78 & 3.04 & & & NS \\
\hline
\end{tabular}

9.5 Correlation between QWL and Components of QWL in SMEs under transformational and transactional leadership style

Below table shows the person correlation coefficient between QWL and Components of QWL under Transformational leadership style and Transactional leadership style.

Table 11

Correlation between QWL and Components of QWL

\section{Dimensions of QWL}

\begin{tabular}{l}
\hline Work Environment \\
Organization Culture \\
Relation \& Co operation \\
Training \& Development \\
Compensation \& Rewards \\
Facilities \\
Job satisfaction \& Job security \\
Autonomy of work
\end{tabular}

Adequacy of Resources
Correlation coefficient Transformational leadership style Transactional leadership style

Under both the leadership style job satisfaction and job security have more significant correlation with the QWL. In case of transformational leadership style autonomy of work (0.630) is less correlated with QWL and in case of transactional leadership Training and development $(r=0.7683)$ has less correlation with QWL.

\subsection{Regression analysis}

The statistical technique that expresses the relationship between two or more variables in the form of equation to estimate the value of a variable, based on the given value of another variable, is called 
regression analysis. The variable whose value is estimated using the algebraic equation is called dependent variable and variable whose value is used to estimate this value is called independent variable. The linear algebraic equation used for expressing a dependent variable in terms of independent variable is called linear regression equation. In this research Quality of Work Life (QWL) is the dependent variable and nine dimensions of QWL are the independent variables or predictors.

\begin{tabular}{ll}
\hline Dimensions of QWL & Symbols \\
\hline Work Environment & C1 \\
Organization Culture & C2 \\
Relation \& Co operation & C3 \\
Training \& Development & C4 \\
Compensation \& Rewards & C5 \\
Facilities & C6 \\
Job satisfaction \& Job security & C7 \\
Autonomy of work & C8 \\
Adequacy of Resources & C9 \\
\hline
\end{tabular}

For all the regression equation, $\mathrm{p}$-value in the Analysis of Variance table $(0.000)$ shows that the model estimated by the regression procedure is significant at a-level of 0.05 . The $\mathrm{R}^{2}$ value indicates that the predictors explain $100 \%$ of the variance in QWL, values indicate that the model fits the data well.

\subsection{Regression equation for QWL and Components of QWL in SMEs under Transformational leadership}

The regression equation for QWL Industry wise under transformational leadership style

$$
\begin{aligned}
\mathrm{QWL}= & 0.00502+0.124 \mathrm{C} 1+0.141 \mathrm{C} 2+0.116 \mathrm{C} 3+0.0791 \mathrm{C} 4+0.102 \mathrm{C} 5+0.100 \mathrm{C} 6 \\
& +0.159 \mathrm{C} 7+0.117 \mathrm{C} 8+0.0596 \mathrm{C} 9
\end{aligned}
$$

From the above regression equation it is identified that for one value of QWL job satisfaction and job security (C7) contributes 0.159 (regression coefficient), this is the maximum contribution and minimum contributor is Adequacy of resources (C9) is 0.0596 . Value of $\mathrm{R}^{2}$ is $1, \mathrm{P}<0.00$ that indicates that QWL accounts $100 \%$ variation in the dependent variable under transformational leadership.

9.8 Regression equation for QWL and Components of QWL in SMEs under Transactional leadership

The regression equation for QWL Industry wise under transactional leadership style

$\mathrm{QWL}=0.00966+0.119 \mathrm{C} 1+0.139 \mathrm{C} 2+0.120 \mathrm{C} 3+0.0799 \mathrm{C} 4+0.103 \mathrm{C} 5+0.0991 \mathrm{C} 6+0.160 \mathrm{C} 7$ $+0.117 \mathrm{C} 8+0.0608 \mathrm{C} 9$

From the above regression equation it is identified that for one value of QWL job satisfaction and job security (C7) contributes 0.16 (regression coefficient), this is the maximum contribution and minimum contributor is Adequacy of resources (C9) is 0.0608 . Value of $\mathrm{R}^{2}$ is $1, \mathrm{P}<0.00$ that indicates that QWL accounts $100 \%$ variation in the dependent variable under transactional leadership.

\section{Conclusion}

\subsection{Quality of Work Life}

The demographical characteristics of the firms like age of the firm, size of the firm and investment on plant and machinery are significantly not associated with the employee Quality of Work Life. That is Quality of Work Life of the employees is independent of demographical characteristic of the firms. 
The demographical characteristics of the firms like age of the firm, size of the firm and investment on plant and machinery are significantly not associated with the leadership styles. That is leadership style is independent of demographical characteristic of the firms. Leadership styles transformational leadership style and transactional leadership style is independent of firm's demographical characteristics.

\subsection{Quality of Work Life and Leadership styles industry wise}

1. Quality of Work Life of employees in SMEs has significant association with the leadership styles. That is quality of Work Life of employees in SMEs is dependent on leadership style like transformational leadership style and transactional leadership style.

2. Under Transformational leadership and Transactional leadership Quality of work life of employees is not associated with demographical characteristics of SMEs like age of the firm, size of the firm and cost of the firm.

\subsection{Components of QWL and leadership styles}

1. Out of nine components of Quality of Work Life three components like work environment, relation and cooperation and autonomy of work has a significant association with leadership style.

2. Other six components like organization culture and climate, training and development, compensation and reward, facilities, job satisfaction and job security and adequacy of resources are not depended on leadership style.

3. Under transformational leadership style job satisfaction and security has high impact and autonomy of work has less impact on employees' quality of Work Life.

4. Job satisfaction and security has high impact and training and development has less impact on Quality of Work Life under transactional leadership style.

\section{References}

Bartlett, J. E., Kotrlik, J. W., \& Higgins, C. C. (2001). Organizational research: Determining appropriate sample size in survey research. Information Technology, Learning, and Performance Journal, 19(1), 43-50.

Bass, B. M., \& Avolio, B. J. (1990). Developing transformational leadership: 1992 and beyond. Journal of European industrial training, 14(5).

Barchiesi, M. A., \& La Bella, A. (2007, August). Leadership Styles of World's most Admired Companies A Holistic Approach to Measuring Leadership Effectiveness. In Management Science and Engineering, 2007. ICMSE 2007. International Conference on (pp. 1437-1447). IEEE.

Berson, Y., Avolio, B. J., \& Kahai, S. (2003), going deeper into building a grounded theory approach: from verification to discovery, in Fred Dansereau, Francis J. Yammarino(ed.) Multi-Level Issues in Organizational Behavior and Strategy (Research in Multi Level Issues, Volume 2)Emerald Group Publishing Limited, pp.143 - 151.

Cooper, R., \& Schindler, P. (1998). Business research methods. $6^{\text {th }}$ ed., Boston: McGraw-Hill.

Cunningham, J. B., \& Eberle, T. (1990). A guide to job enrichment and redesign. Personnel, 67(2), 56-61.

Fang, C. H., Chang, S. T., \& Chen, G. L. (2009, May). Applying Structural Equation Model to Study of the Relationship Model among leadership style, satisfaction, Organization commitment and Performance in hospital industry. E-Business and Information System Security, 2009. EBISS'09. International Conference on (pp. 1-5). IEEE. 
Hian, C. C., \& Einstein, W. O. (1990). Quality of Work Life (QWL): What can unions do. SAM Advanced Management Journal, 55(2), 17-22.

Hackman, J. R., \& Oldham, G. R. (1980). Work redesign.

Hogg, R.V. and Tanis, E.A. (1997). Probability and Statistical Inference, 5th Edition, Prentice-Hall.

Kothari, C. R. (2004). Research methodology: methods and techniques. New Age International.

McNeese-Smith, D. (1995). Job satisfaction, productivity, and organizational commitment: The result of leadership. Journal of Nursing Administration, 25(9), 17-26.

Nahavandi, A. (2006). The art and science of leadership, Ltd. Pearson Education.

Ogbonna, E., \& Harris, L. C. (2000). Leadership style, organizational culture and performance: empirical evidence from UK companies. International Journal of Human Resource Management, 11(4), 766-788.

Omolayo B (2007). Effect of leadership style on job-related tension and psychological sense of community in work organizations: A case study of four organizations in Lagos State, Nigeria. Bangla. e-j. Soc. 4 (2):30-37.

Podsakoff, P. M., MacKenzie, S. B., Moorman, R. H., \& Fetter, R. (1990). Transformational leader behaviors and their effects on followers' trust in leader, satisfaction, and organizational citizenship behaviors. The Leadership Quarterly, 1(2), 107-142.

Prideaux, M., \& Beg, R. (2007). Uncovering leadership issues in Papua New Guinea.

Rethinam, G. S., \& Ismail, M. (2007). Constructs of quality of work life: A perspective of information and technology professionals. European Journal of Social Sciences, 7(1), 58-70.

Rose, R. C., Beh, L., Uli, J., \& Idris, K. (2006). Quality of work life: implications of career dimensions. Journal of Social Sciences, 2(2), 61.

Saraji, G. N., \& Dargahi, H. (2006). Study of quality of work life (QWL). Iranian journal of public health, 35(4), 8-14.

Smith, B.D. (1998) Leadership: Psychology, science and understanding. Ca: Addison-Wesley,686-687

Victor, G. Y. S., \& Soutar, G. N.(2005) The Role Of Ethical Behaviours In The Relations Between Leadership Styles And Job Performance.

Voon, M. L., Lo, M. C., Ngui, K. S., \& Ayob, N. B. (2011). The influence of leadership styles on employees' job satisfaction in public sector organizations in Malaysia. International Journal of Business, Management and Social Sciences, 2(1), 24-32.

Wang, G. Y. X. Z. S. (2008). The impact of transformational leadership style. on organizational performance: the intermediary effects of leader-member exchange. Management Science.

Wang, D., Xue, H., \& Xu, J. (2009, September). The Mechanism of Leadership Styles Affecting Team Innovation in the PRC. In Management and Service Science, 2009. MASS'09. International Conference on (pp. 1-4). IEEE.

Ye, L., Junye, D., \& Yan, M. (2011, May). The relationships between leadership styles and organizational innovation climate: Cases of some high-tech enterprises in Hebei. Business Management and Electronic Information (BMEI), 2011 International Conference on (Vol. 2, pp. 316-319). IEEE. 